\title{
Mouse Colon Adenocarcinoma
}

National Cancer Institute

\section{Source}

National Cancer Institute. Mouse Colon Adenocarcinoma. NCI Thesaurus. Code C120044.

An adenocarcinoma arising from the colon of a mouse. It can be used as a mouse model of the human disease. 